\title{
Ethnoconvenience: A Cousin of Colorism and Colorblindness and a Behavior of Tolerance and Exclusion
}

\author{
Anton Shufutinsky ${ }^{1,2,3,4 *}$ and Noah Shufutinsky ${ }^{5}$ \\ ${ }^{1}$ Organizational Development Graduate Program, Cabrini University, Radnor, PA, USA \\ ${ }^{2}$ Changineering Global, Cheltenham, PA, USA \\ ${ }^{3} N T L$ Institute for Applied Behavioral Science, Washington, DC, USA \\ ${ }^{4}$ Academy of Interdisciplinary Health Science Leaders, Elkins Park, PA, USA \\ ${ }^{5}$ The George Washington University, Washington, DC, USA
}

Submission: December 21, 2018; Published: January 30, 2019

"Corresponding author: Anton Shufutinsky, Organizational Development Graduate Program, Cabrini University, Radnor, Changineering Global, Cheltenham, NTL Institute for Applied Behavioral Science, Washington, Academy of Interdisciplinary Health Science Leaders, Elkins Park, PA, USA

\begin{abstract}
Many organizations have instituted policies of tolerance as official parts of their corporate or agency diversity and inclusion initiatives, and many people have become accustomed to using the term synonymously with acceptance and inclusion. Tolerance, however, despite the likely intended meaning of the term, is a white-centric artifact developed by the empowered in a dominant-subordinated culture, with the word, at its very roots, making the implication that people of color and other minority groups are to be tolerated-accepted against the standards and norms in a culture of eurocentrism and racial privilege. Essentially, attitudes, language, and behaviors of tolerance include a group of behaviors, such as colorblindness, colorism, sameness, centralization, credentializing, and tokenization, among others, that espouse tolerance and therefore, instead of diversity, equity, and inclusion promote toleration and exclusion. We introduce ethnoconvenience as one series of such attitudes and behaviors and define and describe what warrants ethnoconvenience and how it is related to yet differentiated from the other language and practices of tolerance in today's immortalized dominant-subjugated U.S. culture.
\end{abstract}

Keywords: Ethnoconvenience; Tolerance; Racism; Prejudice; Diversity and Inclusion; Stereotyping; Racial Privilege

\section{Introduction}

Racial discrimination continues to be a problem in the United States (U.S.) and globally. Despite great progress over several generations, this pervasive problem exists in U.S. communities and organizations and affects the way that people interact in public as well as the way organizations are designed, developed, and operated. Despite efforts to progress beyond them, there continue to be issues related to race, color, and culture and they have a significant effect on social and economic disparities and prevent equity and inclusion. Government administrators, politicians, academics, community leaders, and organizational executives have worked to improve diversity programs and policies and have created standards and policies designed to minimize or exterminate marginalization. These efforts have increased hiring of people of color globally and have prompted the addition of language of tolerance into many organizational policies and handbooks.

Unfortunately, many do not understand the implications and ramifications of attitudes, language, and behaviors of tolerance which, although designed to prevent bigotry and prejudice, act as contributors to diversity and exclusion rather than inclusion and equity. There are numerous behaviors that fall into this category of tolerance, including one that we introduce that, although related to the others, separates itself. This attitude and behavior is termed ethnoconvenience, and it can promote, preserve, and perpetuate inequality and exclusion in organizations, communities, and society. The purpose of this article is to define, describe, and exemplify ethnoconvenience and discuss how it is related to the other behaviors and attitudes of tolerance, and to further explain the role that it plays in the perpetuation of racial inequality and exclusion in organizations, communities, and in society in general.

\section{Racism, Inequality, Diversity, Inclusion, and Multicul-} turalism

The United States is a nation with a history of being strongly preoccupied with differences, and thus diversity has very much been a matter of identity in the country [1]. Our national construct in the U.S. is one that has been defined as a continuum from a 
dominant versus subordinated culture towards multiculturalism, equity, and inclusion [2]. Moving towards a healthy construction desires the inclusion of subordinated groups, including categories of race, ethnicity, gender, sexual orientation, citizenship status, religion, and ability, and the intersection of these categories [2].

Unfortunately, we are not, as a nation, nor as a people globally, nearing the terminal end of that continuum. Racism has deep, and often horrific roots in the history of the U.S. and the national population, and racism and inequality have long been and continue to be a pervasive social problem in our society, in communities, and in organizations, including occupational settings. It is no secret that the dominant culture in a society, a community, or an organization molds individuals, their attitudes, their beliefs, their values, and their behaviors [3]. In the U.S., the predominant culture of white dominance [2] has shaped the government, laws, social groups, organizations, and the individuals within the population for generations [4]. Certainly, many organizations have figured out the economic, legal, and social benefits of and reasons to diversify the workforce. These organizations have begun to understand that they need to draw the best talent to remain competitive in today's rapidly changing global market and that this talent comes from different demographics in the global population [4-7].

Nevertheless, we still dwell in a racially divided and dominance-driven nation, and this is mimicked in organizations. We must candidly and honestly drive discourse and dialogue and strive not simply for tolerance, which is a byproduct of the raciallydriven culture of dominance, but instead for racial equality, as well as equity in the workplace. James Baldwin stated that the future, and dealing with discrimination and diversity in the future, is our responsibility because we are our only hope [8]. Therefore, it is critical that we address the different language, practices, pathways, and behaviors that continue to perpetuate racism, bigotry, and the dominant-subordinated culture that exists in our society. The word subordinated instead of subordinate is used here because it is a condition that is forced upon the group by a majority or dominant group historically empowered to do so [2].

We posit that a behavior, attitude, or practice, which we call ethnoconvenience, is a distinct, though related, attitude and behavior of tolerance [4,7], as will be discussed throughout the manuscript, and thus is a significant contributor to inequality, inequity, discrimination, and delegitimization, and is a barrier to equality, inclusion, and multiculturalism.

\section{Discussion}

\section{Ethnoconvenience - An Introduction}

Within the problems and continual issues of prejudice and racism in the U.S., one of the biggest purposes for and results from bigotry is delegitimization, which is the categorization of groups into negative social extremes that drive exclusion from the dominant society's definition of human norms and values [9]. Whether purposefully established and instigated, or accidental, delegitimization occurs in society at the national, community, and organization levels.
There are numerous stages in Huntley, Moore \& Pierce's [2] continuum, representing the journey from racial inequality to equity and inclusion, where delegitimization is clearly identifiable. This continuum is a brilliant map of the U.S. social system undergoing transformation, providing a better and more transparent understanding of race dynamics. Combined with the continuum, Huntley's, Moore's \& Pierce's [2] Journey of Race, Color, and Culture explores the complex dynamics in the U.S. and illuminates who we are, as individuals, and how we behave in the context of these dynamics.

Although many are aware of the numerous methods by which delegitimization occurs, and the ways in which racism rears its ugly head, including stereotyping, white privilege, white liberalism, colorblindness, credentializing, and tokenization, among other behaviors associated with the supremacy-driven concept of tolerance, one concept closely related to but separate from these behaviors and attitudes is generally missed in the discussion altogether. This behavior, although sometimes muted in comparison, is no less damaging or problematic in the dynamics of interactions that deal with the problems of racial inequality, inequity, prejudice, and exclusion.

Ethnoconvenience is a close cousin of colorblindness, sameness, colorism, tokenization, and stereotyping, all attitudes and behaviors of tolerance rather than equality and multiculturalism. In short, ethnoconvenience includes the identification and categorization of individuals, and application of values, thoughts, beliefs, and affiliations onto those individuals, based on appearance and assumption. It is, in practice, a way of categorizing someone because it is convenient to an argument, proof of a point being made, or action. Ethnoconvenience, left unattended, affords the perpetrator the ability to proceed with thoughts, behaviors, or treatment towards others with little effort or difficulty, and without alarm of inherent bias or racial privilege. In order to thoroughly understand ethnoconvenience, it is first vital to explore the different related attitudes, practices, and behaviors of tolerance.

\section{Attitudes, Behaviors, and Language of Tolerance}

Tolerance is a term often used to define acceptance, and is commonly referred to in educational, corporate, and government agency policies and procedures in reference to ensuring inclusive environments that are free of racism and bigotry. Nevertheless, the use of the term tolerance, with reference to the social constructs of race, identity, and societal race relations, is one that delays or halts progress towards equity and multiculturalism, and may, on the subconscious level, promote exclusion and continued bigotry [7].

Today, arguably a revived era of pseudo-normalized racial and ethnic upheaval that is both a cause for and a product of police brutality, bigoted demonstrations, riots, politicians' racist remarks, defacement of cultural landmarks, disparate treatment in commercial establishments, and inhumane detention practices, among others, it is not uncommon to hear subject matter experts, reporters, politicians, and media pundits call for sensitivity 


\section{Annals of Social Sciences \& Management studies}

training and increased tolerance in the general population or in organizations.

However, the language and attitude of tolerance in these pleas, as well as those commonly seen in human resources (HR) policies and corporate diversity and inclusion (D\&I) practices, are examples of the perpetuation of this dominant-subordinated behavior, where the mass population is the one that "tolerates" the existence and practices of the "others," the people of color (PoC). Tolerance is a topic of race and power in society, in conjunction with other identities and forms of discrimination [10], although it does not always appear blatant or may not even be recognized by the perpetrators, remaining purposefully or conditionally hidden in their unconscious states, even as a positive instead of negative social element [7].

Table 1: A few examples of attitudes and common statements of tolerance with racist underpinnings.

\begin{tabular}{|c|c|}
\hline Statement or Attitude Category & $\begin{array}{c}\text { Common Attitudes or Statement of Bias, Privilege, Insensitivity, and Racist } \\
\text { Underpinnings-Tolerance }\end{array}$ \\
\hline Tolerance & $\begin{array}{l}\text { "We practice tolerance in this company." } \\
\text { "We're very tolerant of minorities." }\end{array}$ \\
\hline Colorblindness & $\begin{array}{l}\text { "I don't even see color." } \\
\text { "I'm colorblind." }\end{array}$ \\
\hline Sameness & $\begin{array}{l}\text { "We're all the same" } \\
\text { "We are all one race, the human race." }\end{array}$ \\
\hline Tokenization & $\begin{array}{l}\text { "But you're different." } \\
\text { "You speak so well." }\end{array}$ \\
\hline $\begin{array}{l}\text { Ethnoconvenience; Colorism; white Centrism; white } \\
\text { Privilege }\end{array}$ & "But your half white anyway, so your experience is different." \\
\hline Tokenization; Ethnoconvenience; white Centrism & $\begin{array}{c}\text { "But you look white, so you could hide it." } \\
\text { "But Ashkenazi Jews are white anyway, and more European, so how much semitic blood do } \\
\text { they have anyway?" } \\
\text { "But that's a religion, not a race or ethnicity." }\end{array}$ \\
\hline
\end{tabular}

Although many corporations and other organizations have taken to increasing and improving corporate social responsibility (CSR) programs regarding D\&I, many of the policies still tend to result in attitudes and language that, even on subconscious levels, result in behaviors and practices of dominance and subjugation in organizations, providing advantages based on pre-established, long-lasting, habitual and historic cultural artifacts of inequality, including attitudes and common statements that foster or perpetuate exclusion and marginalize or delegitimize PoC, exemplified in (Table 1) [7]. As human beings, and particularly those in leadership and other positions of influence in society, we must recognize the effects of the tolerance practices of colorblindness, sameness, tokenization, colorism, stereotyping, white centrism, model minority status, and ethnoconveniencepractices that perpetuate diversity and exclusion instead of promoting diversity and inclusion. Practices that have been normalized in the greater society in the U.S.

\section{Colorblindness}

A commonly heard response regarding racism is "I don't even see color." While some believe that this is a commendable statement or outlook, it is instead a contributor to the problem of racial inequality. Being colorblind is not a solution for racism. Being colorblind means that there's a failure to identify and recognize the person in question, thus ignoring or rejecting their selves and all those traits and experiences that make them who they are. By stating that one is colorblind, it is implying that $\mathrm{PoC}$ are invisible to them, and this is a failure to recognize one's cultures, rites, rituals, upbringing, and experiences $[2,4]$.
Colorblindness ignores cultural differences instead of honoring them and allows people to ignore the history of white cultural dominance and the experiences of PoC in dealing with this subjugation throughout history. Although people that make these statements may even believe that they are attempting to treat everyone equally, the reality is that it perpetuates the dominantsubordinated culture $[2,7]$. Colorblindness is one attitude and behavior of tolerance and it exhibits a message of ignorance to cultural differences, and even if unintentionally, it compares PoC to white people norms, implying that $\mathrm{PoC}$ are tolerable rather than equal [7].

\section{Sameness}

Sameness, closely tied to colorblindness, is another behavior of tolerance. It is not uncommon for people to make race-associated statements that imply that "we are all the same underneath." Not only is this biologically implausible, it immortalizes privileged and bigoted thinking and behavior. Even people that have been intimately involved in the struggle against bigotry and racism have used these types of statements, probably with the best intentions, but with a subconscious frame of privilege.

In a recent best-selling biographical novel [11], for example, although we cannot presume what thoughts and ideas escaped the author's mind at the time of writing, there is a quote that states that "we are all the same." As explained, this language is problematic for D\&I scholars, applied behavioral scientists, and social science practitioners who focus on D\&I. Like colorblindness, sameness is a concept that perpetuates the dominant-subordinated 
culture $[2,4]$. In the context of the statement that "you're no different than I, we are all the same," sameness practically means whiteness because it positions PoC in white cultural norms, as though they are tolerable now that they have reached the level of white standards and have been proclaimed to be "the same." It discounts the cultural differences and discards experiences with racial injustice and bigotry [2], delegitimizing the struggle. Thus, statements and attitudes like these ignore the uniqueness of our race-based differences, instead discarding the differences we have in upbringing, life experience, rites, and rituals for a proclamation that "you are as good as I am" [7].

\section{Colorism}

Colorism is a persistent problem for PoC in the U.S., and globally, although it is much less focused on in race discourse. In general terms, colorism, which is also sometimes referred to as skin color stratification, is a means by which prejudice occurs not solely based on race and ethnicity, but also on skin color and tone, and other allelic features. In many aspects, this behavior privileges lighter skinned PoC over those with darker skin and has been shown to sometimes cause disparities among people of the same racial background in terms of income, education, housing, employment, and organizational positionality [12]. Historically, the social construct of racism has permitted the dominant culture to not only unequally treat PoC based on race, but also on skin color and darkness, furthermore, creating tension within and between communities of PoC [12]. This behavior has not only perpetuated white privilege and racial bigotry against PoC, but it has sabotaged unity and solidarity between inter- and intra-PoC groups, like the effects of the social construct of model minorities.

Some research shows that $\mathrm{PoC}$ with lighter skin have, as a result of white supremacy and white centrism, enjoyed some level of clear advantage when it comes to economics, employment, and educational disparities, marginalizing individuals with darker skin and limiting opportunity. However, the data also shows evidence of a disparity regarding ethnic authenticity, recognition, and legitimacy, on the contrary being granted to individuals with darker skin, marginalizing and delegitimizing lighter skinned individuals and minimizing their experiences and cultural identities. This practice of colorism is directly related to and part of the larger problem of systematic and systemic racism, both in the U.S. and globally [12], and is a creation of white supremacy and the racist culture in U.S. history.

Although this racist phenomenon against PoC has occurred throughoutgenerations in the U.S., it has somehow goneundetected in the legal and policy infrastructure. In the U.S., colorism is often ignored in the courts as a type or kind of discrimination [13] because although the law includes color as a basis for prohibited discrimination, it has generally been interpreted to mean the same thing as race [14], not including hue, tone, hair color, hair texture, and eye color, among other features.

Colorism expands bigotry from the dominant to the subordinated, turning people of color against one another as a result of skin shade, and based on a eurocentric, white idea of beauty and acceptability. Under generations of exposure to this behavior, Black, Asian, and Latino/a people, among others, have had some of their experiences trivialized and their opportunities minimized.

\section{Hidden or Implicit Bias}

Hidden or implicit biases are automatic, unconscious or subconscious preferences for or against a group or individual. Although implicit biases are not always negative, these preferences act to form the basis for related behaviors - stereotypes, discrimination, and prejudice. Thus, hidden or implicit biases can feed the racially-based disparity in communities and in organizations [15].

These implicit biases affect people's actions and decisions in an unconscious or subconscious manner, with the perpetrators often unaware of their privilege or any intention of control [2], and white privilege often precludes people from recognizing and understanding these hidden biases [16]. Even upon limited recognition of these biases, individuals may still be hesitant to admit that they hold them, often due to personal fragility regarding being viewed in a negative manner [17]. As an outcome, these biases lead to a detachment between intentions and actions, as well as to the inability to address how the biases impact interactions with others in organizations, communities, and societies [7]. Implicit biases can cause people, including group, organizational, or community leaders, to believe that they are being inclusive and accepting of diverse people, diverse thought, and cultures through their policies and practices of tolerance when, in fact, these policies, practices, attitudes, and behaviors of tolerance are exclusionary and prejudiced [7].

\section{white privilege}

white privilege is another relevant factor in the inequitable and disparate practice of tolerance. It is defined as unearned advantage gained for no other reason besides being white in a white-dominant and homophile civilization. This is a strong example of institutional power in a racially stratified society that goes largely unacknowledged to many within that society. white privilege is a crux to this dominant-subjugated culture that has historically had and continues to employ a power-over instead of a power-with relationship about PoC. This privilege has a confirmed effect of forced societal dominance [18], putting PoC in subordinated and unequal statures [2] relative to white society. white privilege is commonly accompanied by resistance and denial from those that benefit from it - even unconscious denial of social favor and the advantages that come with it. The resistance of people to consciously acknowledge this is evidence of how, intentionally or not, power, privilege, and comfort have come to non-PoC, and it benefits them to hold on to it [2].

\section{Tokenization}

With the practice of privilege and implicit bias in place, tokenization is seeded as a relevant behavior and practice, 
exhibited also as a behavior and attitude of tolerance. This behavior occurs or is displayed when individuals from a PoC group are given honorary status within the white group. It is not uncommon to hear from people, when confronted with some act of racism or bigotry, that "I'm not racist, one of my best friends is Black," or a similar statement. Having a friend or an acquaintance that is Black, Jewish, Mexican, Chinese, or disabled does not only not automatically clear someone from being bigoted against those racial, ethnic, or other groups, it displays a level of ignorance and privilege, and can be argued to be an exhibit of the individual's prejudice.

Often, tokenization exists because a person from a different demographic is allowed into the societal circles of the dominant group within the dominant-subjugated culture, at least superficially, because they present themselves in a way that is acceptable to or tolerated by that dominant group, despite their differences [2,7]. In short, this attitude and behavior consists of granting honorary status to select individuals from an out-group into the in-group based on acceptability to and adoption of the ingroup's social norms, although it often comes with the expectation that those tokenized individuals put on airs [7].

Tokenization is often used as a multi-faceted approach to benefit the in-group or individuals in the in-group. It allows the members of that group to set aside their guilt and feel good about their selves for accepting someone Black, Latino/a, Jewish, or Asian, for example, into their group. At the same time, justifications are often made for these "honorary" members. Announcing that "they're different," of course describing difference from others in the out-group rather than honoring the differences from those in the in-group. Plus, this tolerance often comes with additional expectations of not only falling in line but exhibiting loyalty by using the honorary status in order to keep those in the subordinated group "in their places [2]."

Tokenization does, by means of definition, exhibit acceptance. However, this is not an inherent acceptance based on equity, and can be termed modern-day acceptance, meaning that the individual is accepted into the mould and is given a title of equal dependent on the evaluation against dominant-driven, pre-determined standards, in this case, white standards [7]. This modern-day acceptance means that the vision of equality and justice is based on white-centric standards rather than being inherently equal based on humanity. This, of course, is not equality and equity, but rather a faux acceptance and an attitude of tolerance, preserving the power-over model and historic dominant-subordinated culture.

\section{Stereotyping}

Stereotypes and prejudice are influenced by both individual self as well as social motives, the perceiver's focus of attention, group membership, and the configuration of stimulus cues. Individual characteristics of members of groups have shown to influence the extent to which stereotypes and prejudice are activated, and the extent to which they are automatic [19]. Effectually, the study of stereotypes is the study of many aspects of social psychology, including group membership, intergroup relations, and group dynamics, as well as neurobiology and neuropsychology. However, from a fundamental perspective, stereotyping requires an understanding of human nature, particularly relevant to neurocognitive fundamentals [20]. Psychologists have shown the relationship between both neurocognitive and social dynamics that participate in the formation of stereotyping. Stereotypes are beliefs, regardless of accuracy or truth, about another group in terms of personality, attributions, or behaviors. They are often based on prejudicial thoughts and beliefs, and often create negative attitudes toward those groups - attitudes that express negative affective or emotional reactions [9,21].

It is through a lack of knowledge or understanding that prejudicial stereotypes often form, and it is often through experiences with an individuals or small samples that stereotypes are generated and inaccurately applied to entire groups. Unfortunately, these stereotypes can lead to learned reactions and behaviors that are unjustified, such as disparity and inequity in law enforcement and judicial action, employment interviews, workplace promotions, banking decisions, property rental, and educational opportunities, among others.

\section{Behaviors and Human Factors Contributing to Ethno- convenience}

\section{Visual Assumption}

People are quick to make visual assumptions or to deduce conclusions based on what they see immediately in front of them. They often act based on these visual experiences or the visual evidence before them. Although what they see may be true to them, these so-called truths are directly based on their personal experience and social construct, depending heavily on culture, upbringing, training, experience, socialization, politics, and other factors. But these assumptions and so-called truths are often not evidence-based, and are even decided upon very simplistic, rudimentary observational behavior.

Amy Herman [22] explains in Visual Intelligence how individuals often make decisions based on assumptions that they believe are evidence-driven because it, whatever it may be, is occurring or has occurred directly in front of their eyes. However, Herman explains that most people may observe, but do not truly see what it is that stands before them. They make assumptions and deductions without getting a deeper look at and understanding of scenarios that transpire right in front of them. These assumptions are often inaccurate, wrong, and potentially damaging to investigations, interactions, relationships, organizations, or communities. Such is also sometimes the case regarding people. People are often perceived solely based on visual assumption, without a deeply rooted knowledge or understanding of their background, both physical and social. This type of behavior often contributes to stereotyping and serves as a base for ethnoconvenience. 


\section{Inattentional Blindness}

As fore-mentioned, Herman [22] discusses the idea of visual intelligence not as a means of exploring more than what people see, but rather to take a deeper dive into what is right in front of them, to analyze the scenario from every angle, and to pull new or more detailed meaning from it, thus better observing their situations and finding, describing, and defining the fine data $[22,23]$, and not making assumptions and deductions that are emotion- rather than evidence-based. Very often, people see the scenario or surroundings that are right in front of them, but do not see or interpret the details in the scenario or the picture.

This inability to truly see what is directly in front of them is termed inattentional or unintentional blindness. This inattentional blindness phenomenon suggests that when focus is placed exclusively on a specific part of a concept, behavior, or image, the other details tend to fade into the background, regardless of whether they are in plain view [22], and decisions are made based solely on what one sees or perceives, regardless if it is real. Furthermore, most people do not believe that they experience inattentional blindness because they lack the awareness of it and they lack, as fore-mentioned, the personal useof-self-as-instrument skills to recognize this [22,23]. Combined, visual assumption and inattentional blindness create a lattice for stereotyping and ethnoconvenience.

Ethnoconvenience: Cousin to Colorblindness and Colorism

The practice and language of identifying someone based solely on thoughts, beliefs, ideals, perception, interpretation, and visual appearance, and to make assumptions regarding beliefs and acceptable behavior based on those characterizations is what we define as ethnoconvenience, because in a multitude of ways, it enables the perpetrator to view the individual however it is convenient for him or her, making assumptions based on the selfmisplaced internal conveniences.

In short, ethnoconvenience can be interpreted as the perceiver's cognitive laziness in the management of potential complex reality or data. The practice of ethnoconvenience ignores data that is either unavailable, unseen, unknown, or uncomfortable and instead makes determinations, definitions, and decisions based solely on assumptions that are in fact based on personal experiences, beliefs, or ideas. These beliefs and ideas may originate from the fore-mentioned behaviors of tolerance, including white privilege and implicit bias, as well as the related colorblindness, sameness, colorism, and stereotyping. Based on these biases and beliefs, individuals often commit ethnoconvenient behaviors and categorizations as a result of the integration of visual assumption and inattentional blindness. Ethnoconvenience can take many shapes and forms, and they are all related yet slightly separate or different from the other attitudes and behaviors of tolerance. Multiple examples are provided in the following text, but this is not an all exhaustive list or exhibit.
One example of ethnoconvenience includes the basic categorization of an individual's race or ethnicity simply based on their physical feature appearance, including skin color, hair color, hair texture, eye shape and size, nose shape and size, among other features. For instance, assuming someone is of white race or ethnicity because of their skin color, and either avoiding the possibility or ignoring the knowledge that the individual is Jewish, is an example of ethnoconvenience. A similar example is assuming that a Black individual is racially white due to the outward appearance of light skin tone, blonde hair, and green eyes. Although this is ethnoconveniencing, this is the simplest form. People make determinations based on observation, and it is not always easy to identify the race or ethnicity based on physical features. Many people could make this mistake, and it is often human nature to do so.

On the other hand, knowing that someone is Black, Jewish, Native American, or other background and ignoring that information because of their outward appearance is not as simple, and is a blatant act of either white-centric tolerance or intolerance. This is the second type or example of ethnoconvenience. This is either ignoring the race, ethnicity, or culture that you know exists, or ignoring what is observable. For instance, identifying an outwardly appearing Orthodox Jew as White, despite facial features and cultural dress, or failing to identify someone who is Black Hispanic as such, paying attention only to the black skin color and ignoring the Latino/a race and culture of the individual. A different example of this, though more difficult to identify, is the assumption that family members are not related because of skin color differences, such as making the assumption that a darker skinned Black woman is a nanny or a babysitter when she is caring for a lighter skinned or white skinned child, ignoring the possibility or even the likelihood that she is the child's mother.

A third type of ethnoconvenience involves ignoring or devaluing an individual's race, ethnicity, or culture because of existing data. For instance, knowing that someone has distant Apache or Navajo ancestry, but dismissing or denying that tie because it is distant or low percentage. A similar example has to do with the knowledge and understanding that an individual is Jewish but ignoring or dismissing the genetic-racial and ethnic heritage information and categorizing ethnic Jewry solely as religious, and the individual based on skin color. Often, this is done for convenient purposes in a debate or to attempt to prove a point, and thus, the perpetrator conveniently ignores or dismisses ethnic or cultural belonging for political or other gain, such as arguments regarding indigeneity to a land or region.

The next example of ethnoconvenience is closely related to colorism and stereotyping and may, but should not, be confused with colorism. As fore-mentioned, peer-reviewed study data has shown disparities between lighter and darker skinned individuals of different races. The data has shown that some lighter skinned individuals may have experienced economic, educational, or employment advantages over PoC with darker skin, and that some darker skinned individuals may have experience more acceptance 
and been credited with a higher level of ethnic authenticity and legitimacy than their lighter counterparts $[12,14]$. Although these study data may be true, the white-centric assumption regarding these experiences is not colorism, but rather ethnoconvenience. In other words, the assumption that someone of lighter skin has had an easier experience or has not experienced discrimination at the same or at any level is ethnoconvenience.

A further and related type of ethnoconvenience also having to do with colorism and stereotyping has to do with applying an assumption of appearance on an entire race, ethnicity, or culture. While stereotyping generally has to do with applying experience, observation, or knowledge of personality, attributions, or behaviors of an individual to an entire group, ethnoconvenience has to do with applying what one believes of an entire group, regarding appearance, to every individual. An example would be to assume that all Mexican people are Hispanic, or all Jews are white, ignoring the diversity of the ethnic Jewish diaspora, such as African, Latino/a, Sephardic, or Mizrahi Jewry, or that there are Native American Mexicans that do not have Hispanic origins.

The above is not an exhaustive list and does not constitute every type or example of ethnoconvenience, but rather provides some examples. It is evident from these examples that these are usually related to visual assumption and inattentional bias, as well as with colorblindness, colorism, stereotyping, and implicit bias, and as such, they are examples of attitudes or behaviors of tolerance that can create intolerant environments. Ethnoconvenience can lead to numerous social ramifications and can affect victims of its practice in numerous ways.

Ignoring an individual's ethnicity, race, culture, and identity can leave those individuals feeling misidentified, misunderstood, and insulted, and the ethnoconvenient acts of purposefully dismissing an individual's race, ethnicity, or culture can create a negative, dispute-like, clashing relationship. Additionally, the failure to identify and the blatant mis-categorization of individuals can leave them feeling marginalized and delegitimized. People are proud of their heritage, culture, and background, and strongly identify with their races, ethnicities, and cultures as major definitions of their selves [24].

Ethnic pride and belonging are two main parts of ethnic identity, so it is not unlikely that separating or questioning people's identity from their present beings can affect feelings of pride and belonging and cause problems for the individuals, and for the group or organization that they belong to or interact in. These practices and behaviors of ethnoconvenience, whether blatant, inattentional, or implicit, can thus serve as tools of deculturalization. Furthermore, mistaking, avoiding, ignoring, or dismissing people's races, ethnicities, and cultures can place them into different identity groups, and potentially into the whitecentric dominant group in the dominant-subjugated culture-a group to which they do not belong or did not extensively experience through life, thus creating unwanted tokenization or forced social assimilation.
Ultimately, ethnoconvenience places an incorrect, false, or incomplete identity on $\mathrm{PoC}$ as a result of assumptions made under implicit bias and white privilege for convenient personal, group, organizational, or political agendas, among others. This results in identifying people incorrectly, often as white, and either misplacing or minimizing their experiences, their individualities, their identities, and their struggles. It is understandable how ethnoconveniencing people and misidentifying them as white, model minority, or dominant-belonging serves to delegitimize their identities and their struggles in national dominantsubjugated environments. Altogether, these behaviors can have a social and psychological effects on individuals and create feelings of denigration, like other types of racist or racially-driven behaviors do.

\section{Conclusion}

Racism has been a pervasive problem over the course of history in the United States. Even with great progress over generations, there continue to be issues related to race, color, and culture and a continuing disparity regarding equity and inclusion based on race and ethnicity across the nation, in communities and in organizations. Despite the progress made, the dominantsubjugated culture is perpetuated, and as a result as well as a cause for perpetuation, certain attitudes, language, and behaviors termed as tolerance, masqueraded as positive movement towards equity, inclusion, and multiculturalism, are attitudes and behaviors that preserve, promote, and propagate inequality and exclusion. Among them is the attitude and behavior of ethnoconvenience.

This manuscript defines the practice and behavior of ethnoconvenience and exhibits how it is closely related to and how it accompanies white privilege, hidden bias, colorblindness, sameness, colorism, stereotyping, and tokenization, among others, as an attitude, language, and behavior of tolerance, where tolerance is a term of racially-driven exclusion. The article provides examples of ethnoconvenience and identifies the effects that ethnoconvenience has on individuals that experience it, including insult, conflict, denigration, deculturalization, and delegitimization.

\section{Disclaimer Statement}

This manuscript was not funded or sponsored by the Academy of Interdisciplinary Health Science Leaders (AIHSL), Changineering Global (CG), NTL Institute (NTL), Cabrini University, or The George Washington University (GWU). The positions, statements, interpretations, and professional opinions expressed in this manuscript are those of the authors alone, and do not represent the stances, findings, opinions, or positions of AIHSL, Cabrini University, GWU, CG, or NTL.

\section{References}

1. Appiah, KA (2005) The Ethics of Identity. Princeton University Press: Princeton, New Jersey, USA.

2. Huntley, Moore, R, Pierce, C (2017) Journeys of Race, Color, \& Culture: From Racial Inequality to Equity \& Inclusion. New Dynamics Publications: Laconia, NH, USA. 
3. Hofstede, Hofstede, GJ, Minkov, M (2010) Cultures and Organizations Software of the Mind - Intercultural Cooperation and Its Importance for Survival ( $3^{\text {rd }}$ edn), McGraw Hill: New York, USA.

4. Shufutinsky, A Shufutinsky, B Shufutinsky, D Shufutinsky, Sibel et al. (2018) Holder's Nation of Cowards: Exploring the Fallacy of a Post-Racial America. International Journal of Interdisciplinary and Multidisciplinary Studies 4(4): 1-55.

5. Jayne, ME, Dipboye, RL (2004) Leveraging diversity to improve business performance: Research findings and recommendations for organizations. Human resource management 43(4): 409-424.

6. Plummer, D, Jordan, CG (2007) Going Plaid. OD PRACTITIONER 39(2)

7. Shufutinsky, A., Shufutinsky, B. (2019). The Attitude and Language of Tolerance and How They Perpetuate Exclusion. Unpublished, Currently under peer-review..

8. Popova, M (2015) A rap on race: Margaret Mead and James Baldwin's rare conversation on foregiveness and the difference between guilt and responsibility, USA.

9. Bar-Tal, D (1989) Delegitimization: The extreme case of stereotyping and prejudice. In Stereotyping and prejudice pp. 169-182.

10. Lee, KS, Calvin, JR (2006) Stronger relationships, stronger communities: Lessons from a regional intergroup grant initiative. American journal of community psychology 37(3-4): 349-356.

11. Landrieu, M (2018) In the Shadows of Statues: A white Southerner Confronts History. Viking: New York, USA.

12. Hunter, M (2007) The persistent problem of colorism: Skin tone, status, and inequality. Sociology Compass 1(1): 237-254.

13. Banks, TL (1999) Colorism: A darker shade of pale. UCLA L Rev 47: 1705.
14. Harris, AP (2008) From color line to color chart: Racism and colorism in the new century. Berkeley J Afr-Am L \& Pol'y 10(1): 52.

15. Jolls, C, Sunstein, CR (2006) The law of implicit bias. Cal L Rev 94(4): 969-996.

16. Branscombe, NR, Schmitt, MT, Schiffhauer (2007) Racial attitudes in response to thoughts of white privilege. European Journal of Social Psychology 37(2): 203-215.

17. Diangelo, R (2018) White Fragility: Why It's So Hard for White People to Talk About Racism. Beacon Press: Boston, Massachusetts, USA.

18. Pinterits, EJ, Poteat, VP, Spanierman (2009) The White Privilege Attitudes Scale: Development and initial validation. Journal of Counseling Psychology 56(3): 417.

19. Blair, IV (2002) The malleability of automatic stereotypes and prejudice. Personality and Social Psychology Review 6(3): 242-261.

20. Bar-Tal, Graumann, Kruglanski, AW, Stroebe (2013) Stereotyping and prejudice: Changing conceptions. Springer Science \& Business Media, Germany, Europe.

21. Fiske, ST (1998) Stereotyping, prejudice, and discrimination. The handbook of social psychology 2: 357-411.

22. Herman, AE (2016) Visual Intelligence: Sharpen Your Perception, Change Your Life. Houghton Mifflin Harcourt: Boston, USA.

23. Shufutinsky, A (2019) Attention to Detail: A Book Review of Amy Herman's Visual Intelligence. International Journal of Interdisciplinary and Multidisciplinary Studies 5(1).

24. Valk, A, Karu, K (2001) Ethnic attitudes in relation to ethnic pride and ethnic differentiation. The Journal of social psychology 141(5): 583601.

\begin{tabular}{|l|}
\hline \multicolumn{1}{|c|}{ Your next submission with Juniper Publishers } \\
will reach you the below assets \\
- Quality Editorial service \\
- Swift Peer Review \\
- Reprints availability \\
- E-prints Service \\
- Manuscript Podcast for convenient understanding \\
- Global attainment for your research \\
- Manuscript accessibility in different formats \\
( Pdf, E-pub, Full Text, Audio) \\
- Unceasing customer service \\
Track the below URL for one-step submission \\
https://juniperpublishers.com/online-submission.php
\end{tabular}

